\title{
Interactive comment on "Petrophysical and mechanical rock property database of the Los Humeros and Acoculco geothermal fields (Mexico)" by Leandra M. Weydt et al.
}

\section{Leandra M. Weydt et al.}

weydt@geo.tu-darmstadt.de

Received and published: 10 October 2020

Correspondence to: Leandra M. Weydt (weydt@geo.tu-darmstadt.de)

Author's comment on "Referee comment 1 - Review on Petrophysical and mechanical rock property database of the Los Humeros and Acoculco geothermal fields (Mexico)" by Anonymous Referee 1 We would like to thank the anonymous referee \#1 (R1) for the helpful and valuable comments to improve our manuscript. In the following sections, we are addressing the referee's remarks and suggestions and present changes made in the manuscript. 
Referee 1 - C2 line 68: "Another relevant, and recent, paper that the authors could consider citing here is Heap et al. (2020, JVGR). Heap, M. J., Gravley, D. M., Kennedy, B. M., Gilg, H. A., Bertolett, E., \& Barker, S. L. (2020). Quantifying the role of hydrothermal alteration in creating geothermal and epithermal mineral resources: The Ohakuri ignimbrite (Taupo Volcanic Zone, New Zealand). Journal of Volcanology and Geothermal Research, 390,106703." Answer: Thank you very much for this very up to date reference. We added the citation "Heap et al. (2020)" to line 68.

Referee 1 - C2 lines 90, 107, 254: "Data is plural." Answer: Thank you very much for the detailed proofreading. The manuscript was checked again and the mistake was corrected accordingly.

Referee 1 - C2 line 146:" "Samples. . .were collected several times. . ." suggests that the same block of rock was collected several times. Suggest to reword." Answer: Thank you very much for this hint. We reworded the sentence as followed: "Whenever possible, each geological unit was sampled several times at different outcrop locations to cover the unit's heterogeneity and only samples with an overall fresh appearance unaffected by weathering were considered."

Referee1 - C2 line 265:" I suspect the authors mean "too friable" rather than "too brittle"." Answer: At this point, we wanted to describe samples that tend to break easily, which prohibited proper conduction of rock mechanical tests in terms of test duration and sample preparation. This accounts for limestones collected close to dykes and intrusive bodies containing several calcite-filled fractures, but also intensively hydrothermally altered lavas collected from a large fault zone located west of the Los Humeros Volcanic Complex. Thus, both words would be correct. We changed "brittle" to "fragile" to describe this phenomenon in a more generalized way.

Referee 1 - C2 line 329:" You mean "Table 2"?" Answer: Thank you very much for pointing this out. This sentence refers to the general description of the database presented in section 4 (lines 245 to 255) and not to Table 2 presented in the manuscript. 
The database is provided in an Excel file containing two datasheets. The first datasheet contains all information on the analyzed petrophysical properties, while the second one includes all chemical data. To avoid any misunderstandings, we changed "the second table" to "the second datasheet of the database".

Referee 1 - C2 line 350:" A temperature of 105 _C might be high enough to encourage thermal microcracking or damage clays. Can the authors comment on the suitability of using this temperature? Are the authors sure the materials were not affected?" Answer: The samples were prepared according to internationally recognized standard methods (ASTM D4543, 2019, ASTM D4525, 2013), which recommend a temperature of approximately $100{ }^{\circ} \mathrm{C}$ for common rock samples. The majority of the samples contain no clays and samples affected by hydrothermal alteration such as the reservoir core samples contain mineral assemblages developed at much higher temperatures. The reservoir core samples were stored for more than twenty years at the CFE core storage. Chemical and petrographic analyses did not reveal any retrograde/low-temperature alteration products caused by weathering or humid storage conditions. Likewise, only outcrop samples with an overall fresh appearance were collected. A good indicator for mass losses and mineralogical changes are also the temperature and heat flow curves of the specific heat capacity measurements, whereby sample material was heated at a steady rate from 20 up to $200{ }^{\circ} \mathrm{C}$. Furthermore, the sample weight was recorded before and after the measurements and significant mass losses due to the collapse of clay minerals were not observed. Thus, the effect of swelling clays or clays that are sensitive to temperature changes between 20 and $105^{\circ} \mathrm{C}$ on the petrophysical rock properties can be neglected. In addition, the effect of thermal microcracking caused by thermal stress at temperatures between 20 and $100{ }^{\circ} \mathrm{C}$ can be neglected. Recent studies have shown that microfracture development and fracture opening start at $200{ }^{\circ} \mathrm{C}$ in basaltic lavas and tuff, at $500{ }^{\circ} \mathrm{C}$ in dolerite and gabbro (Siratovich et al., 2011), and at about $180^{\circ} \mathrm{C}$ in high-strength concrete (Heap et al., 2013). Even thermal stressing of up to $750^{\circ} \mathrm{C}$ and subsequent cooling did not significantly impact the petrophysical and rock mechanical behavior of andesitic lavas (Heap et al., 2014, 2018), 
while it had a more variable impact on tuff samples above $350{ }^{\circ} \mathrm{C}$ (Heap et al., 2012). Thereby, the thermal resilience of the samples can be explained by the thermal stability of the mineral assemblage (temperature-dependent break down of each mineral) and the presence of pre-existing microcracks (Heap et al., 2018). Generally, microcracks develop due to stress caused by mineral expansion and contraction during temperature increase and decrease, respectively. However, already existing microcracks close and reopen as a response to volumetric changes caused by temperature changes without further microcracking. Thus, samples that already underwent (thermal) fracturing and metamorphic processes do not tend to develop new microfractures, until they are exposed to higher temperatures than previously. This phenomenon is called the Kaiser temperature-memory effect and is presented in e.g. Vinciguerra et al. (2005), Heap et al. (2014, 2018), and recently in Vagnon et al. (2020 submitted), which also includes samples from this study (limestones from Las Minas). Especially, the metamorphic and hydrothermally altered rocks used in this study contain numerous fractures and microcracks and experienced temperatures much higher than $105^{\circ} \mathrm{C}$. Thus, the probability of rock property changes caused by the drying procedure exceeding the error of the measurement devices is very small.

Referee 1 - C2 line 353 and 439:" Can the authors comment on the effectiveness of saturating samples by leaving them submersed in water? For tight rocks, it seems doubtful that water would have penetrated thin pores/cracks. Errors resulting from incomplete saturation would influence, for example, the porosity measurements using the triple-weight method (Lines 365 and 370)." Answer: The majority of the porosity data provided in the database were performed using the combined helium and powder pycnometer method. The porosity measurements using the triple weighing and caliper method were performed additionally to the pycnometer method to compare and validate different analytical approaches. They were conducted according to internationally recognized testing methods (ISRM, 1981, and ISRM, 1979) and were repeated several times to provide a statistically verified mean value. However, the results of the different measurement techniques applied to the same sample material are well in line with

Interactive comment 
each other. Variations in particle density between different methods applied on the same samples range between $0.3-2.9 \%$ (coefficient of variation) for limestones with porosities smaller than $3 \%$ and $0.5-3.5 \%$ for pyroclastic rocks with porosities between 11 and $15 \%$. The variations in bulk density between the different methods are in the same range. Therefore, we can argue that the applied methods produce measurement results with sufficient precision.

Interactive

comment

Referee 1 - C2 line 360:" For those unsure of the meaning of "effective porosity", I would add "i.e. connected porosity" in parentheses here." Answer: Agreed. The sentence was changed to "Afterwards porosities were calculated from the resulting differences in volume and represent the gas-effective porosity, also known as connected porosity."

Referee 1-C2 line 373:" What was the range of plug length? Measurements on "short" samples of a homogeneous sandstone were recently shown to provide reliable permeability values, see Heap (2019). These authors argued that permeability measurements on "short"samples are reliable as long as the pore/grain/crystal size is small compared to the length/diameter of the sample. Heap, M. J. (2019). The influence of sample geometry on the permeability of a porous sandstone. Geoscientific Instrumentation, Methods and Data Systems, 8(1), 55-61." Answer: The length of the plugs used for permeability measurements ranges between $\sim 20 \mathrm{~mm}$ and $\sim 80 \mathrm{~mm}$. Thus, short and longer samples are considered in this study. We agree that measurements on small scale samples are reliable as long as the samples represent the minimal representative elementary volume (REV; Ringrose and Bentley, 2015) as described in section 4.1 line $316 f$.

Referee 1 - C3 line 377:" Gas permeability measurements for high-permeability samples and/or when using high flow rates likely also require a Forchheimer correction. Did the authors check for this?" Answer: Thank you very much for this question. The recorded flow rates of the gas permeability measurements performed at TUDA, GFZ and UNAM were checked for turbulent fluid flow (Forchheimer effect, Forchheimer, 
1901). Therefore, the volumetric flow rates were plotted against the corresponding reciprocal permeability determined for each differential pressure. A Forchheimer correction is needed, whenever the data show a positive linear trend. This step needs to be performed before the Klinkenberg correction (gas slippage effect, Klinkenberg, 1941) to ensure that the recorded results meet the requirements of Darcy's law, which assumes laminar fluid flow (Kushnir et al., 2018, Heap, 2019). However, the recorded results obtained in this study didn't show a positive linear trend. Furthermore, we identified that permeability measurements corrected after Forchheimer were in most cases equal to the original values or at least in the same order of magnitude as the original values. Thus, a correction after Forchheimer was not necessary, because the corrected values are within the error range of the measurement device.

Referee 1 - C3 line 381:" “. . . at five pore fluid pressure levels. . ." " Answer: Agreed. We changed the sentence according to the reviewer's suggestion.

Referee 1 - C3 line 407:" Elastic wave velocities were measured parallel to the sample axis?" Answer: Thank you very much for that comment. The elastic wave velocities were measured along the sample axis. The transmitter-receiver transducers were pressed centrically against each parallel surface of the samples using a contact pressure of about 1 bar. To further clarify, we added "along the sample axis" in line 406 and the following sentence "Thereby, the transducers were pressed against the parallel surfaces of the samples using a contact pressure of about 1 bar." in line 411.

Referee 1 - C3 line 425:" Can the authors provide more information as to how the saturated velocities were measured? On samples submersed in water? Or were the samples wrapped in cling film and quickly measured to avoid desaturation?" Answer: Before measurements, the samples were stored in degassed and de-ionized water. After preparing the device, the samples were immediately installed between the transducers to perform the measurements. This procedure takes only a few seconds and the transmitted signals can be recorded a few times until the sample starts to desaturate, which of course affects the measurements. Wrapping up the samples in cling film 
would not be practical for two reasons: 1) The cling film would not stick to the surface, because the sample is completely wet and wrapped in a water film, and 2) this step requires to take the sample out of the water before the measurement resulting in an earlier desaturation of the sample.

Referee 1 - C3 line 474:" If the authors prefer to use "G-Modulus", I would also put "shear modulus" in parentheses to avoid any confusion." Answer: Thank you very much for this comment. We added "also known as shear modulus" to line 473.

Referee 1 - C3 line 479:" This should be "load at failure/maximum load" and "crosssectional area"." Answer: Thank you very much for this remark. We changed the sentence to "where $F$ is the load at failure $[N]$ and $A$ is the cross-sectional area of the sample $\left[\mathrm{mm}^{2}\right]$."

Referee 1 - C3 line 484:" Do the authors mean here that they used a constant loading rate of $0.5 \mathrm{kN} / \mathrm{s}$ ? It's not clear. Written as it is, it suggests that the loading rate was variable and that the maximum was $0.5 \mathrm{kN} / \mathrm{s}$." Answer: Thank you very much for pointing this out. At TU Darmstadt the destructive tests using the hydraulic uniaxial press were usually performed at $0.5 \mathrm{kN} \mathrm{s}-1$. The exception form very soft or fragile samples, such as ignimbrites, pumice or intensively fractured limestones. For these samples, the load rate was individually reduced to 0.25 or $0.1 \mathrm{kN} \mathrm{s}-1$ to meet the test requirements and to ensure the minimal test duration. Otherwise, the sample would break too quickly or immediately after starting the measurement resulting in invalid test results. We changed the passage accordingly.

Referee 1 - C3 line 485:" Do the authors mean the loading rate?" Answer: Yes, this is correct. We added "rate" to line 485 to avoid any misunderstandings.

Referee 1 - C3 line 490:" What type of sensor? Strain gauges?" Answer: For the determination of the axial displacement and lateral extension of the plugs during cyclic loading, LVDT sensors (linear variable differential transformer) were used. The detailed setup is described in DIN 18141-1:2014-05 and Mutschler (2004). To clarify, we added 
"(LVDT sensors)" to line 490.

Referee 1 - C3 line 508:" Can the authors elaborate on what they mean by "tension controlled"?" Answer: Tension controlled means the loading of the sample is configured in MPa s-1. However, this sentence needs to be corrected. The samples at TU Delft were also tested 'force-controlled' at $0.15 \mathrm{kN} \mathrm{s}-1$.

Referee 1 - C3 line 519:" They were loaded diametrically in compression?" Answer: Yes, this is correct. The samples were loaded diametrically in compression. The detailed test setup is described in ASTM 3967 (2016) and Lepique (2008). To avoid misinterpretations, we added "also known as diametrical compression" to line 519.

Referee 1 - C3 line 537:" The triaxial experiments were performed on dry samples?" Answer: This is correct. The triaxial testing device at TU Darmstadt is equipped to perform measurements on dry samples only. Unless otherwise stated, all measurements are performed on oven-dry samples (see Figure 3 in the manuscript). Only thermal conductivity, thermal diffusivity, P-wave and S-wave velocity, as well as electric resistivity, were analyzed at dry and saturated conditions. To point this out, "oven-dry" was added to line 539 .

Referee 1 - C3 line 607:" See also the study by Eggertsson et al. (2020), who measured samples taken from the Krafla geothermal system in Iceland. Eggertsson, G. H., Lavallée, Y., Kendrick, J. E., \& Markússon, S. H. (2020). Improving fluid flow in geothermal reservoirs by thermal and mechanical stimulation: The case of Krafla volcano, Iceland. Journal of Volcanology and Geothermal Research, 391, 106351." Answer: Thank you very much for referring to this article. We added the quotation Eggertsson et al. (2020) to line 608.

Referee 1 - C4 line 669:" I think the authors should include an additional paragraph(s) that states that large-scale modelling, such as fluid circulation models, require upscaled values not those measured in the laboratory. I think it would be beneficial for the reader if the authors explain the issues surrounding using laboratory-measured

Interactive 
values in large-scale models and discuss/present existing methods typically used to upscale such values." Answer: We agree that a comment on this topic would be very ESSDD beneficial for the reader. However, upscaling of reservoir data and problems that occur using laboratory measurements in large-scale models is a broard topic and could easily fill a whole new paper, which is beyond the scope of this article. The applied upscaling methods and problems that might occur, strongly depend on the purpose, size, and accuracy of the model. As it is not possible to go into much detail in this manuscript, we added a short paragraph to section 7 Discussion to shortly discuss the required steps before using the data in reservoir models.

Further modifications: The numbers included in Table 2 in section 6 "Status of the database" were adjusted as further measurement results were added to the database.

\section{âĂČ References}

ASTM D3967-16, Standard Test Method for Splitting Tensile Strength of Intact Rock Core Specimens, ASTM International, West Conshohocken, PA, USA, 5 pp., DOI:10.1520/D3967-16, 2016.

ASTM D4525-13e2: Standard Test Method for Permeability of Rocks by Flowing Air, ASTM International, West Conshohocken, PA, USA, 5 pp., DOI: 10.1520/D452513E02, 2013.

ASTM D4543-19: Standard Practices for Preparing Rock Core Specimens and Determining Dimensional and Shape Tolerances, ASTM International, West Conshohocken, PA, USA, 13 pp., DOI: 10.1520/D4543-19, 2019.

Bär, K., Arndt, D., Fritsche, J.-G., Kracht, M., Hoppe, A., and Sass, I.: 3D-Modellierung der tiefengeothermischen Poten-ziale von Hessen - Eingangsdaten und Potenzialausweisung, Z.dt. Ges. Geowiss., 162, 371-388, 2011.

DIN 18141-1:2014-05: Baugrund - Untersuchung von Gesteinsproben - Teil 1: Bestimmung der einaxialen Druckfestigkeit, Beuth, 14 pp., 
https://dx.doi.org/10.31030/2100323, 2014.

Eggertsson, G. H., Lavallée, Y., Kendrick, J. E., and Markússon, S. H.: Improving ESSDD

fluid flow in geothermal reservoirs by thermal and mechanical stimulation: The case of Krafla volcano, Iceland. Journal of Volcanology and Geothermal Research, 391, 106351, 2020.

Forchheimer, P.:Wasserbewegung durch Boden, Z. Ver. Dtsch. Ing., 45, 1782-1788, 1901. Heap, M. J.: The influence of sample geometry on the permeability of a porous sandstone. Geoscientific Instrumentation, Methods and Data Systems, 8(1), 55-61, 2019.

Heap, M.J., Lavallée, Y., Laumann, A., Hess, K.U., Meredith, P.G., Dingwell, D.B.: How tough is tuff in the event offire? Geology 40 (4), 311-314, 2012.

Heap, M. J., Lavallée, Y., Laumann, A., Hess, K.-U., Meredith, P. G., Dingwell, D. B., Huismann, S., and Weise, F.: The influence of thermal-stressing (up to $1000^{\circ} \mathrm{C}$ ) on the physical, mechanical,and chemical properties of siliceous-aggregate, high-strength concrete, Construction and Building Materials, 42, 248-265, 2013.

Heap, M.J., Lavallée, Y., Petrakova, L., Baud, P., Reuschlé, T., Varley, N.R., Dingwell, D.B.: Microstructural controls on the physical and mechanical properties ofedificeforming andesites at Volcán de Colima, Mexico. J. Geophys. Res. Solid Earth119 (4), 2925-2963, 2014.

Heap, M. J., Coats, R., Chen, C., Varley, N., Lavallée, Y., Kendrick, J., Xu, T., Reuschlé, T.: Thermal resilience of microcracked andesitic dome rocks. Journal of Volcanology and Geothermal Research, 367, 20-30, doi:10.1016/j.jvolgeores.2018.10.021, 2018.

ISRM: Suggested methods for determining the uniaxial compressive strength and deformability of rock materials, International Society for Rock Mechanics, Pergamon Press, 137 - 138, 1979.

ISRM: Suggested Methods - Rock characterization testing and monitoring, Ed. E.T. 
Brown, published for the commission on testing methods, International Society for Rock Mechanics, Pergamon Press, 210 pp., 1981.

Klinkenberg, L. J.: The permeability of porous media to liquids and gases, Drilling Production Practice, API, 200-213, 1941.

Kushnir, A. R. L., Heap, M. J., and Baud, P.: Assessing the role of fractures on the permeability of the Permo-Triassic sandstones at the Soultz-sous-Forêts (France) geothermal site, Geothermics, 74, 181-189, https://doi.org/10.1016/j.geothermics.2018.03.009, 2018.

Lepique, M.: Empfehlung Nr. 10 des Arbeitskreises 3.3 "Versuchstechnik Fels" der Deutschen Gesellschaft für Geotechnik e. V.: Indirekter Zugversuch an Gesteinsproben - Spaltzugversuch, Bautechnik, 85, 623-627, DOI: 10.1002/bate.200810048, 2008.

Mutschler, T.: Neufassung der Empfehlung Nr. 1 des Arbeitskreises "Versuchstechnik Fels" der Deutschen Gesellschaft für Geotechnik e. V.: Einaxiale Druckversuche an zylindrischen Gesteinsprüfkörpern, Bautechnik, 81, 825-834, doi: 10.1002/bate.200490194, 2004. Ringrose, P., and Bentley, M.: Reservoir Model Design, Springer Netherlands, 249 pp., http://dx.doi.org/10.1007/978-94-007-5497-3, 2015.

Siratovich, P. A., Sass, I., Homuth, S., and Bjornsson, A.: Thermal Stimultaion of Geothermal Reservoirs and Laboratory Investigation of Thermally Induced Fractures, GRC Transactions, 35, 1529-1536, 2011.

Vagnon; F., Colombero, C., Comina, C., Ferrero, A. M., Mandrone, G., Missagia, R., Vinciguerra, S. C.: Temperature effects on physical properties of carbonate rocks, Rock Mechanics and Geotechnical Engineering, 2020 in review.

Vinciguerra, S., Trovato, C., Meredith, P.G., Benson, P.M.: Relating seismic velocities, thermal cracking and permeability in Mt. Etna and Iceland basalts. Int. J. Rock 
Mech.Min. Sci. 42 (7-8), 900-910, 2005.

ESSDD

Please also note the supplement to this comment:

https://essd.copernicus.org/preprints/essd-2020-139/essd-2020-139-AC1-

supplement.pdf

Interactive comment on Earth Syst. Sci. Data Discuss., https://doi.org/10.5194/essd-2020-139, 2020. 